\title{
X-RAY SPECTROSCOPY OF SOLAR ACTIVE REGIONS DURING THE THIRD SKYLAB MISSION
}

\author{
J. P. PYE, R. J. HUTCHEON, J. H. PARKINSON*, and K. A. POUNDS \\ Dept. of Physics, University of Leicester, England
}

Summary. This paper describes the analysis of soft X-ray spectra of solar active regions observed on a Skylark sounding rocket flight. The experiment was launched from Woomera, South Australia, at 0535 UT on 26th November 1973. The payload consisted of 3 plane scanning. Bragg crystal spectrometers, covering the wavelength range 4 to $23 \AA$; and collimated to 3 arc min FWHM. The instrument was the same as that used by Parkinson $(1972,1973)$. The launch was part of a collaborative observing program with American Science \& Engineering who obtained X-ray photographs of the Sun with the S0-54 ATM X-ray telescope, simultaneously with the Leicester observations. We report preliminary results for McMath region 12624 (S10 W28). This region was observed about $60 \mathrm{~min}$ after the peak of an importance $-\mathrm{N}$, class $\mathrm{CO}$ flare.

In He-like ions the intensity ratio of the resonance line to dielectronic recombination satellites is sensitive to temperature. This temperature dependence has been calculated by Gabriel (1972). We have measured the ratios, and, using the stronger satellites in He-like $\mathrm{O}, \mathrm{Ne}, \mathrm{Mg}, \mathrm{Si}$, have derived electron temperatures for each ion (Table I).

\section{TABLE I}

Temperatures derived from satellite to resonance line intensity ratios in He-like ions

\begin{tabular}{llr}
\hline Ion & $\begin{array}{l}\text { Satellite to resonance line } \\
\text { photon intensity ratio, } \\
\end{array}$ & $T_{\mathrm{e}}\left(10^{6} \mathrm{~K}\right)$ \\
\hline & $\frac{I\left(1 s^{2} 2 s^{2} S_{1 / 2}-\left(1 s 2 p^{1} P\right) \cdot 2 s^{2} P_{1 / 2,3 / 2}\right.}{I\left(1 s^{2} S_{0}-1 s 2 p^{1} P_{1}\right)}$ & \\
\hline O VII & $\leqslant 0.04_{-0.04}^{+0.08}$ & $\geqslant 1.1_{-0.4}$ \\
Ne IX & $0.011 \pm 0.004$ & $6.3_{-1.2}^{+2.7}$ \\
Mg XI & $0.042 \pm 0.009$ & $6.4_{-0.7}^{+1.1}$ \\
Si XIII & $\leqslant 0.14 \pm 0.14$ & $\geqslant 5.5_{-0.7}$
\end{tabular}

Analysis of the observed intensities of several of the resonance lines of the $\mathrm{H}$ - and $\mathrm{He}-$ like ions by the method of Batstone et al. (1970) indicates a total emission measure, in the temperature interval 1.5 to $6.5 \times 10^{6} \mathrm{~K}$, of about $2.2 \times 10^{47} \mathrm{~cm}^{-3}$.

\footnotetext{
* Present address: Mullard Space Science Laboratory, University College London, England.
} 
Measurements of the wavelengths and relative intensities of $\mathrm{Ne}$ IX lines and the dielectronic satellite lines are in good agreement with the calculations of Gabriel (1972). Three unclassified lines which may be due to satellites with the outer electron having $n \geqslant 3$ are observed at 13.463, 13.472 and $13.490 \AA$. The last 2 lines have been previously observed by Parkinson (1971). Several other lines which occur in the same wavelength range (13.26-13.83 $\AA$ ) have been tentatively identified as transitions in Fe XVIII, XIX, XX.

We have obtained relative intensities of $n=3 \rightarrow 2$ and $4 \rightarrow 2$ lines of $\mathrm{Ne}$-like $\mathrm{Fe}$ and $\mathrm{Ni}$ and compared them with the calculations of Loulergue and Nussbaumer (1973, 1974). For the observed transitions there is good agreement between the measured and predicted intensity ratios. In cases where a statistically significant signal $(\gtrsim 4 \sigma)$ is not observed, the upper limits obtained for the intensities are consistent with the calculations. For the Fe XVII $n=3 \rightarrow 2$ transitions the present observations are in good agreement with the observed intensity ratios of Parkinson (1973). The unpublished calculations of Loulergue and Nussbaumer are preliminary figures only.

\section{Acknowledgments}

The authors wish to express their thanks to Drs Loulergue and Nussbaumer for permission to quote their work in advance of publication. R.H. acknowledges receipt of an SRC Fellowship and J.P.P. acknowledges receipt of an SRC research studentship.

\section{References}

Batstone, R. M., Evans, K., Parkinson, J. H., and Pounds, K. A.: 1970, Solar Phys. 13, 389.

Gabriel, A. H.: 1972, Monthly Notices Roy. Astron. Soc. 160, 99.

Loulergue, M. and Nussbaumer, H.: 1973, Astron. Astrophys. 24, 209.

Loulergue, M. and Nussbaumer, H.: 1974, Private communication.

Parkinson, J. H.: 1971, Nature Phys. Sci. 233, 44.

Parkinson, J. H.: 1972, Nature Phys. Sci. 236, 68.

Parkinson, J. H.: 1973, Astron. Astrophys. 24, 215. 